\title{
Neurocognitive Outcomes in Pediatric Brain Tumors Survivors
}

\author{
Daniela Rizzo', Laura Peruzzi ${ }^{1}$, Giorgio Attinà ${ }^{1}$, Silvia Triarico ${ }^{1}$, Palma \\ Maurizi $^{1}$, Antonio Ruggiero ${ }^{1 *}$ \\ ${ }^{1}$ Division of Pediatric Oncology, Catholic University of Rome, Largo A. Gemelli \\ 8, 00168 Rome, Italy.
}

Correspondence: Antonio Ruggiero, MD, Division of Paediatric Oncology, A. Gemelli Hospital, Catholic University of Rome, Largo A. Gemelli 8, 00168, Rome. Phone: +39 06 3058203, Fax: +39 06 3052751, Email: antonio.ruggiero@unicatt.it.

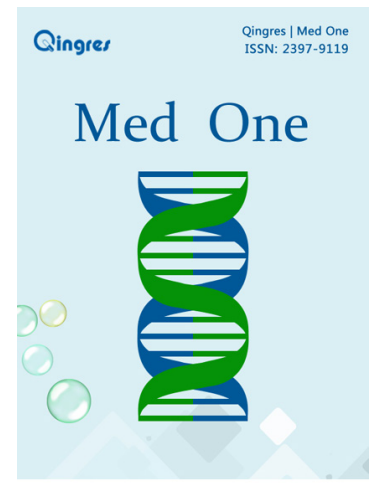

http://mo.qingres.com

\section{GOPEN ACCESS}

DOI: $10.20900 / \mathrm{mo} .20170015$

Received: May 8, 2017

Accepted: July 12, 2017

Published: August 25, 2017

Copyright: ๑2017 Cain et al. This is an open access article distributed under the terms of the Creative Commons Attribution License, which permits unrestricted use, distribution, and reproduction in any medium, provided the original author and source are credited.

\section{ABSTRACT}

Neurocognitive disorders are a common long-term effect in brain tumor survivors. The rate of intelligence quotient (IQ) decline is associated with a several risk factors, including tumor location, younger age at time of treatment, treatment intensity, in particular use of radiotherapy and radiotherapy dose, as well as clinical variables such as hydrocephalus and presence of epilepsy. Demyelinization represents the most important alteration following radiation: loss of cerebral white matter is related to IQ decline, due to damage of the complex information transmission network connecting the various brain areas.

Recently, combined chemo-radiotherapeutic approaches and new technologies in radiation therapy have enabled to lower the frequency of neurocognitive deficits and improve the quality of life of paediatric brain tumours survivors.

Keywords: Neurocognitive impairment; Children; Brain tumor; Cancer surivor

\section{INTRODUCTION}

Tumours of the central nervous system (CNS) are the most common form of solid tumours in childhood, accounting for $20 \%$ of all pediatric malignancies ${ }^{[1,2]}$. Embryonal tumours and low-grade gliomas are the most common brain tumors in children, followed by high-grade glioma, brainstem glioma and ependymoma ${ }^{[3]}$. There are two peaks in the incidence of brain tumours in children and adolescents. The first peak occurs the first decade of life a second much larger peak occurs in late adolescence and early adulthood.

Most children who have survived brain tumours have required surgery and focal or craniospinal irradiation (CSI), with or without systemic chemotherapy ${ }^{[4-7]}$. The improvement in the effective therapy of childhood CNS tumors has resulted in a substantial increase in cure 
rate and survival. However, neurocognitive disorders and sometimes severe disabilities have been documented in $40-100 \%$ of long-term survivors ${ }^{[8-10]}$.

\section{PRINCIPAL RISK FACTORS FOR COGNITIVE IMPAIRMENT}

Neurocognitive late effects in childhood brain tumor survivors are relatively common and can be highly debilitating.

Intelligence quotient (IQ) measure, with a normative mean score of 100 , is the most common method used to evaluate neurocognitive deficits.

A decline in IQ has been frequently associated with a decline in areas of attention, working memory, academic achievement and language ${ }^{[11-13]}$. Moreover, several studies report difficulties in perception and estimation of time, fine motor coordination, visual motor and visual spatial skills in pediatric brain tumor survivors ${ }^{[14-18]}$.

The severity of intellectual outcomes of children with brain tumours depend on different factors. The influence of tumors at diagnosis has recently been studied in adults, whereas only few articles have evaluated the neuropsychological deficits in children before treatment ${ }^{[19]}$.

The tumour location is an important factor that causes selective site-dependent deficits. Infratentorial tumours are associated with a more limited cognitive decline than supratentorial tumours, even when radiotherapy is not used ${ }^{[19]}$. In particular, luvone L. et al showed that all children with mental retardation at diagnosis had cortical tumors involving the mesial regions of the temporal lobes. Left hemispheric lesions are more likely to be associated with verbal deficits, whereas right hemispheric lesions are associated with visual perceptual deficits ${ }^{[20]}$. Moreover, hemispheric tumours result in lower $I Q$ than tumours of the third or fourth ventricle, although children with fourth ventricle tumours show significant declines in their IQ over time.

Tumor volume is a less crucial factor than site for cognitive deficits. Small tumors in critical areas may have a greater impact on neurocognitive outcome than some large tumors.

Symptom duration and the presence of epilepsy are the main clinical factors affecting cognitive status at diagnosis ${ }^{[19]}$. In epileptic children neurocognitive outcome is markedly impaired and declines with time. In particular, in children with grade III epileptic syndromes receiving several antiepileptic drugs maximum cognitive impairment was found, as the result of seizures and pharmacological agents ${ }^{[21]}$.

Obstructive hydrocephalus also plays a role in neurocognitive outcomes in pediatric brain tumors survivors. The level of intracranial pressure and, above all, the duration of the pressure on the fibres of the white matter, mainly of the frontal lobes, are the main factors causing mental deterioration in children with hydrocephalus ${ }^{\text {[22-24] }}$

Despite the use of computer-guided neurosurgical techniques, surgical resection may add further damage to those already existing, due to prolonged retraction of the frontal lobes to reach tumours located elsewhere. Moreover in patients with posterior fossa tumours the incision or destruction of the cerebellar vermis causes complex alterations in social and communicative behaviour ${ }^{[25-27]}$.

Only a small percentage of children affected by brain tumor can be cured by surgery alone. Post-surgical treatment, including chemotherapy and radiotherapy (RT), is based on the histology, presence of metastatic lesions at diagnosis and extent of resection. The potentially devastating effects of RT on growing individuals are well known. Several studies have demonstrated marked losses of IQ of up to 30 points or more which are most predominant in young children, particularly those less than seven or eight years of age ${ }^{[28]}$. In one study of 56 pediatric brain tumor survivors in whom 22 received radiation therapy, IQ scores were less than 90 in $68 \%$ of survivors treated with RT, compared with $18 \%$ of non-irradiated patients [28]. Hirsch et al compared a series of children irradiated for a medulloblastoma with a series of children with cerebellar astrocytoma treated with surgery alone ${ }^{[22]}$. Global IQ exceeded 90 in 2 and $62 \%$, school performance was altered in 75 and $27 \%$, and behaviour was compromised in 93 and $59 \%$ respectively. Moreover, Grill et al analysed 31 children with posterior fossa tumours treated with RT and off therapy for at least 1 year. Patients were divided into 3 groups according to the CSI doses. Neurocognitive deficits occurred in most of the patients, even after posterior fossa irradiation only. Full-scale IQ score was related to CSI dose and was 84.5, 76.9, and 63.7 for $0 \mathrm{~Gy}, 25 \mathrm{~Gy}$, and 35 Gy of CSI, respectively ${ }^{[29]}$. Two independent studies, with 22 and 36 children respectively, have shown the benefit on cognition of lowering the CSI from 35 to $25 \mathrm{~Gy}$ in children with medulloblastoma [22, 30]. This has been the rationale to decrease the craniospinal dose from 36 to $23.4 \mathrm{~Gy}$ in standard risk medulloblastoma, establishing better cognitive outcome after craniospinal dose reduction ${ }^{[31]}$.

However, despite reductions in CSI dosing and efforts to limit the boost volume, the age of the 
patient at treatment remains the most important risk factor for neurocognitive deficits among survivors of brain tumors ${ }^{[31]}$. Very young children are more vulnerable to the effects of the RT and intellectual deficits are greater in survivors who are treated with RT at a younger age than older patients ${ }^{[32,33]}$. A retrospective study on 62 children with different brain tumours described neurocognitive outcome 3-20 years following irradiation ${ }^{[34]}$. The most serious neurocognitive deficits were identified in children younger than 5 years at diagnosis. IQ was in the normal range in patients older than 11 year, whereas patients aged $6-11$ years were stratified into intermediate risk.

Moreover, Mulhern et al. performed a retrospective study on average-risk (AR) patients with medulloblastoma and found that patients receiving standard-dose CSI (36 Gy) and patients younger at time of treatment showed lower IQ than patients receiving reduced dose CSI (23.4 Gy) and aged $>8.8$ years $^{[13]}$. However, in a subsequent prospective study, even the AR patients who had received reduced-dose CSI presented a decline of 4.3 IQ points per year over a 3-year period from treatment ${ }^{[17]}$.

\section{PATHOPHYSIOLOGY OF LATE CNS DAMAGE}

During the first 6 years of life, cerebral development is characterized by cellular and axonal hypertrophy, multiplication of dendrits, interneuronal connections and development of myelin that continues after birth into the third decade of life ${ }^{[35,36]}$. Patterns of myelination differ across brain regions: the brain stem and cerebellar areas myelinate first, followed by the cerebral hemispheres and the anterior portions of the frontal lobes. The connections between myelinated axons in different brain areas support the cognitive functions ${ }^{[37]}$.

Cerebral irradiation is responsible of neurotoxicity and cognitive deficits in childhood brain tumor survivors, by white-matter necrosis and demyelinization. Several studies have evaluated toxic effects of RT on white matter and damage of the information transmission network connecting the various brain areas.

Pathogenesis is still unclear. It could be related to alterations of the endothelial cells or of the oligodendrocytes that produce myelin. In children and in adults underwent RT cerebral radionecrosis has been reported. The risk has been estimated to 5 $\%$ at 55 Gy fractionated, $15 \%$ at 60 Gy, and $20 \%$ at $65 \mathrm{~Gy}^{[38]}$.
Moreover necrotizing leukoencephalopathy and mineralizing micro-angiopathy have been described ${ }^{[39,40]}$, characterized by a gradual decreased alertness and intellectual decline ${ }^{[41]}$. Neuropathologically, necrotic lesions in the periventricular white matter have been reported and neocalcifications, especially in the basal ganglia, have been identified in mineralizing microangiopathy.

Reddick et al compared children irradiated for a medulloblastoma with a series of children with low grade tumours of the posterior fossa who had received surgery alone. Survivors of medulloblastoma had a significantly smaller volume of cerebral white matter, a greater volume of cerebrospinal fluid, and an equal volume of grey matter ${ }^{[42]}$. As expected, IQ scores were significantly lower in survivors of medulloblastoma, associated with volumes of cerebral white matter ${ }^{[12]}$. Subsequently, Reddick et al. showed that decrease in the volume of cerebral white matter in patients with medulloblastoma underwent CSI was more rapid in patients receiving 36 Gy than in patients receiving 23.4 Gy craniospinal irradiation ${ }^{[43]}$.

\section{CONCLUSIONS}

Neurosurgeons, paediatric oncologists, and radiation oncologists have been successful in improving cure rates for most types of childhood brain tumours. Nevertheless, the risks of neurocognitive impairment remain substantial. Tumor location, symptom duration, presence of epilepsy, dose of RT, volume of the brain that receives treatment and age of the patient at treatment are the major determinants of cognitive performance. To date, RT remains a key modality in the curative treatment approach of patients with brain tumors. To reduce neurocognitive morbidity, new protocols have been designed to limit radiation dose using risk-adapted irradiation dosing. Moreover, new techniques of conformal radiation have been introduced in order to enable precise delivery of RT with less damage to the surrounding brain tissue.

In children with brain tumors a neuropsychological surveillance should be routine in order to optimize their outcomes, by a early and preemptive intervention.

\section{CONFLICTS OF INTEREST}

The authors declare that there is no conflict of interest regarding the publication of this paper. 


\section{REFERENCES}

1. Habrand JL, De Crevoisior R. Radiation therapy in the management of childhood brain tumors. Child's Nerv Syst. 2001; 17: 121-133.

2. Smith M, Gloeckler RL. Childhood cancer: Incidence, survival, and mortality. New York, Lippincott Williams \& Wilkins; 2002.

3. Gurney JG, Severson RK, Davis S, Robinson $\mathrm{LL}$. Incidence of cancer in children in the United States. Cancer. 1995; 75: 2186.

4. Rizzo D, Ruggiero A, Martini M, Rizzo V, Maurizi P, Riccardi R. Molecular Biology in Pediatric High-Grade Glioma: Impact on Prognosis and Treatment. Biomed Res Int. 2015; 2015 : 215135.

5. Rizzo D, Ruggiero A, Amato M, Maurizi P, Riccardi R. BRAF and MEK inhibitors in pediatric glioma: new therapeutic strategies, new toxicities. Expert Opin Drug Metab Toxicol. 2016; 12: 1397-1405.

6. Ruggiero A, Rizzo D, Attinà G, Lazzareschi I, Mastrangelo S, Maurizi P, Migliorati R, Bertolini P, Pastore M, Colosimo C, Riccardi R. Phase I study of temozolomide combined with oral etoposide in children with recurrent or progressive medulloblastoma. Eur J Cancer. 2010; 46: 2943-2949.

7. Cefalo G, Massimino M, Ruggiero A, Barone G, Ridola V, Spreafico F, Potepan P, Abate ME, Mascarin M, Garrè ML, Perilongo G, Madon E, Colosimo C, Riccardi R. Temozolomide is an active agent in children with recurrent medulloblastoma/primitive neuroectodermal tumor: an Italian multi-institutional phase II trial. Neuro Oncol. 2014; 16: 748-753.

8. Lassaletta A, Bouffet E, Mabbott D, Kulkarn AV. Functional and neuropsychological late outcomes in posterior fossa tumors in children. Childs Nerv Syst. 2015; 31: 1877-1890.

9. Ajithkumar T, Price S, Horan G, Burke A, Jefferies $S$. Prevention of radiotherapy-induced neurocognitive dysfunction in survivors of paediatric brain tumours: the potential role of modern imaging and radiotherapy techniques. Lancet Oncol. 2017; 18: e91-e100.

10. Chieffo D, Tamburrini G, Frassanito P, Arcangeli V, Caldarelli M, Di Rocco C. Preoperative neurocognitive evaluation as a predictor of brain tumor grading in pediatric patients with supratentorial hemispheric tumors. Childs Nerv Syst. 2016; 32: 1931-1937.

11. Ris MD, Packer R, Goldwein J, Jones-Wallace D, Boyett JM. Intellectual outcome after reduced-dose radiation therapy plus adjuvant chemotherapy for medulloblastoma: a Children's Cancer Group study. J Clin Oncol. 2001; 19: 3470-3476.

12. Mulhern RK, Reddick WE, Palmer SL, Palmer SL, Glass JO, Elkin TD, Kun LE, Taylor J, Langston J, Gajjar A. Neurocognitive deficits in medulloblastoma survivors and white matter loss. Ann Neurol. 1999; 46: 834-841.

13. Mulhern RK, Kepner JL, Thomas PR, Armstrong FD, Friedman HS, Kun LE. Neuropsychologic functioning of survivors of childhood medulloblastoma randomized to receive conventional or reduced-dose craniospinal irradiation: a Paediatric Oncology Group study. J Clin Oncol. 1998; 16: 1723-1728.

14. Ris MD, Noll RB. Long-term neurobehavioral outcome in pediatric brain-tumor patients: review and methodological critique. J Clin Exp Neuropsychol. 1994; 16: 21-42.

15. Dennis M, Spiegler BJ, Hoffman HJ, Hendrick EB, Humphreys RP, Becker LE. Brain tumors in children and adolescents. I. Effects on working, associative and serial-order memory of $I Q$, age at tumor onset and age of tumor. Neuropsychologia. 1991; 29: 813-827.

16. Packer RJ, Sutton LN, Atkins TE, Radcliffe J, Bunin GR, D’Angio G, Siegel KR, Schut L. A prospective study of cognitive function in children receiving whole-brain radiotherapy and chemotherapy: 2-year results. J Neurosurg. 1989; 70: 707-713.

17. Johnson DL, McCabe MA, Nicholson HS, Joseph AL, Getson PR, Byrne J, Brasseux C, Packer RJ, Reaman G. Quality of long-term survival in young children with medulloblastoma. J Neurosurg. 1994; 80: 1004-1010.

18. Reddick WE, White HA, Glass JO, Wheeler GC, Thompson SJ, Gajjar A, Leigh L, Mulhern RK. Developmental model relating white matter volume with neurocognitive deficits in paediatric brain tumour survivors. Cancer. 2003; 97: 25122519.

19. luvone L, Peruzzi L, Colosimo C, Tamburrini G, Caldarelli M, Di Rocco C, Battaglia D, Guzzetta F, Misciagna S, Di Giannatale A, Ruggiero A, Riccardi R. Pretreatment neuropsychological deficits in children with brain tumors. Neuro Oncol. 2011; 13: 517-524.

20. Ellenberg L, McComb JG, Siegel SE, Stowe S. Factors affecting intellectual outcome in pediatric brain tumor patients. Neurosurgery. 1987; 21: 638-644.

21. Ruggiero A, Rizzo D, Mastrangelo S, Battaglia 
D, Attinà G, Riccardi R. Interactions between antiepileptic and chemotherapeutic drugs in children with brain tumors: is it time to change treatment? Pediatr Blood Cancer. 2010; 54: 193198.

22. Hirsch JF, Renier D, Czernikow P, Benvenist L, Pierre-Kahn A. Medulloblastoma in childhood. Survival and functional results. Acta Neurochir. 1979; 48: 1-15.

23. Riva D, Pantaleoni C, Milani N, Belani FF. Impairment of neuropsychological functions in children with medulloblastomas and astrocytomas in the posterior fossa. Child's Nerv Syst. 1989; 5: 107-110.

24. Riva D, Milani N, Giorgi C, Pantaloni C, Zorzi C, Devoti M. Intelligence outcome in children with shunted hydrocephalus of different etiology. Child's Nerv Syst. 1994;10:70-73.

25. Giorgi C. Computed assisted planning of stereotactic neurosurgery. Child's Nerv Syst. 1989; 5: 299-305.

26. Riva D, Pantaleoni C, Devoti M, Saletti V, Nichelli F, Giorgi C. Late neuropsichological and behavioral outcome of children surgically treated for craniopharingioma. Child's Nerv Syst. 1998; 14: 179-184.

27. Riva D, Giorgi C. The cerebellum contributes to higher functions: evidence from a series of children surgically treated for posterior fossa tumours. Brain. 2000; 123: 1051-1061.

28. Lannering B, Marky I, Lundberg A, Olsson E. Long-term sequelae after pediatric brain tumors: their effect on disability and quality of life. Med Pediatr Oncol. 1990; 18: 304-310.

29. Grill J, Renaux VK, Bulteau C, Viguier D, LevyPiebois C, Sainte-Rose C, Dellatolas G, Raquin MA, Jambaque I, Kalifa C. Long-term intellectual outcome in children with posterior fossa tumors according to radiation doses and volumes. Int $\mathrm{J}$ Radiat Oncol Biol Phys. 1999; 45: 137-145.

30. Kieffer-Renaux V, Bulteau C, Grill J, Kalifa C, Viguier D, Jambaque I. Patterns of neuropsychological deficits in children with medulloblastoma according to craniospatial irradiation doses. Dev Med Child Neurol. 2000; 42: 741-745.

31. Mulhern RK, Palmer SL, Merchant TE, Wallace D, Kocak M, Brouwers P, Krull K, Chintagumpala M, Stargatt R, Ashley DM, Tyc VL, Kun L, Boyett J, Gajjar A. Neurocognitive consequences of risk-adapted therapy for childhood medulloblastoma. J Clin Oncol. 2005; 23: 55115519.
32. Walter AW, Mulhern RK, Gajjar A, Heideman RL, Reardon D, Sanford RA, Xiong X, Kun LE. Survival and neurodevelopmental outcome of young children with medulloblastoma at St Jude Children's Research Hospital. J Clin Oncol. 1999; 17: 3720-3728.

33. Jannoun L, Bloom HJ. Long-term psychological effects in children treated for intracranial tumors. Int J Radiat Oncol Biol Phys. 1990; 18: 747-753.

34. Palmer SL, Goloubeva O, Reddick WE, Glass JO, Gajjar A, Kun L, Merchant TE, Mulhern RK. Patterns of intellectual development among survivors of pediatric medulloblastoma: A longitudinal analysis. J Clin Oncol. 2001; 19: 2302-2308.

35. Dobbing J, Sands J. Quantitative growth and development of human brain. Arch Dis Child. 1973; 48: 757-767.

36. Sowell ER, Thompson PM, Holmes CJ, Jernigan $T L$, Toga AW. In vivo evidence for post-adolescent brain maturation in frontal and striatal regions. Nat Neurosci. 1999; 2: 859-861.

37. Filley CM. The behavioral neurology of cerebral white matter. Neurology. 1998; 50: 1535-1540.

38. Marks JE, Wong J. The risk of cerebral radionecrosis in relation to dose, time and fractionation. Prog Exp Tumor Res. 1985; 29: 210-218.

39. Korinthenberg R. Irradiation induced brain dysfunction in children. Recent Results Cancer Res. 1993; 130: 199-207.

40. Poplack DG, Brouwers PI. Adverse sequelae of central nervous system therapy. Clin Oncol. 1985; 4: 263-285.

41. Dupuis-Girod S, Hartmann O, Benhammou E, Doz F, Mechinaud F, Bouffet E, Coze C, Kalifa C. Will high dose chemotherapy followed by autologous bone marrow transplantation supplant cranio-spinal irradiation in young children treated for medulloblastoma? J Neurooncol. 1996; 27: 87-98.

42. Reddick WE, Mulhern RK, Elkin TD, Glass JO, Merchant TE, Langston JW. A hybrid neural network analysis of subtle brain volume differences in children surviving brain tumours. Magn Reson Imaging. 1998; 16: 413-421.

43. Reddick WE, Russell JM, Glass JO, Xiong X, Mulhern RK, Langston JW, Merchant TE, Kun LE, Gajjar A. Subtle white matter volume differences in children treated for medulloblastoma with conventional or reduceddose cranial-spinal irradiation. Magn Reson Imaging. 2000; 18: 787-793. 